\title{
Homens e suas percepções sobre planejamento familiar - vasectomia
}

\section{Men and their perceptions on family planning - vasectomy}

\author{
Camila Melo Borba ${ }^{1}$ Edirlei Machado Dos-Santos ${ }^{2}$ Patricia da Silva Pires ${ }^{3}$ - Michela Macedo Lima Costa ${ }^{4}$
}

\section{RESUMO}

Objetivou-se identificar e analisar as percepções de homens no grupo etário de 25 à 59 anos, sobre o planejamento familiar e a vasectomia. Pesquisa qualitativa, com dados coletados em entrevistas semiestruturadas e analisadas pela técnica análise de conteúdo temática, no período de junho à julho de 2016. Participaram 13 homens residentes da área de abrangência de uma Unidade de Saúde da Família, no município de Vitória da Conquista, Bahia. Depreenderam-se duas categorias: Olhares masculinos sobre o planejamento familiar, tendo como subcategorias: a importância do planejamento familiar sob a ótica masculina; fragilidade acerca do conhecimento/participação masculina no planejamento familiar; e 0 Antagonismo da vasectomia, tendo como subcategorias: benefícios da vasectomia; estereótipos/desconhecimento. Os participantes apresentaram conhecimento superficial quanto aos métodos contraceptivos e sobrecarga direcionada à mulher diante da escolha e utilização dos mesmos. Observou-se a ambivalência de opiniões, por um lado os homens sabem sobre a eficácia da vasectomia, mas ainda apresentam medos relacionados ao procedimento. Uma atenção de qualidade no planejamento familiar requer dos profissionais de saúde preparação para assistir aos homens; implementação de estratégias para que os homens sejam mais atuantes nas ações de planejamento, para que haja destruição dos estereótipos que permeiam à vasectomia. Palavras-chave: Planejamento Familiar; Vasectomia; Saúde do Homem; Enfermagem.

\begin{abstract}
The aim is to identify and analyze the perceptions of men in the age group between 25-59 years on family planning and vasectomy. Qualitative research, with data collected in semi-structured interviews and analyzed by thematic content analysis technique, in the period June to July 2016.13 resident men of the spanning area of Unit of Health of the Family had participated, in the city of Vitória da Conquista, Bahia. It had inferred in two categories: male Glances on family planning, with the subcategory: the importance of family planning under the male perspective; fragility about knowledge/male participation in family planning; and the Vasectomy antagonism, with subcategories: vasectomy benefits; stereotypes/ignorance. The participants presented superficial knowledge regarding contraception and there is directed at women on overload of choice and use of them. It was noted the ambivalence of opinions, on the one hand the men know about the effectiveness of a vasectomy, but still have fears related to the procedure. Quality care in family planning requires health professionals preparing to watch the men; implementing strategies for which men are more active in planning, as far as to destroy the stereotypes that pervade the vasectomy.
\end{abstract}

Keywords: Family Planning; Vasectomy; Men's Health; Nursing.

${ }^{3}$ Enfermeira. Doutora em Enfermagem. Docente da Universidade Federal da Bahia - UFBA - IMS/CAT. Vitória da Conquista, BA, Brasil. E-mail: patriciaspires@gmail.com 


\section{INTRODUÇÃO}

Existem múltiplas políticas públicas que contribuem para a diversidade de serviços de saúde para a população, contudo, a sistematização de ações direcionadas à população masculina é incipiente. Devido a uma maior necessidade, a atenção à saúde do homem passou a ser uma prioridade do governo nos últimos anos. Frente ao exposto, o Ministério da Saúde elaborou a Política Nacional de Atenção Integral a Saúde do Homem (PNAISH) ${ }^{1}$.

A PNAISH está direcionada aos homens no grupo etário compreendido entre 25 e 59 anos, e tem por objetivo qualificar a saúde da população masculina na perspectiva de linhas de cuidado que resguardam a integralidade da atenção. Além disso, busca destacar questões que levam a melhoria das condições de vida dos indivíduos, sendo elas: tabagismo, álcool, hipertensão e doenças de causa externas, tendo como pauta a promoção da saúde e a prevenção da doença. A violência, morbimortalidade e a saúde sexual e reprodutiva são questões que direcionam a PNAISH².

No que diz respeito ao planejamento familiar e aos direitos reprodutivos e sexuais, é necessário superar a restrição da responsabilidade das práticas contraceptivas sobre as mulheres e assegurar aos homens o direito à participação na regulação da fecundidade e na reprodução ${ }^{3}$.

A atenção em anticoncepção tem por conduta oferecer informações e aconselhamento de anticoncepcionais que sejam cientificamente aceitos e que não coloquem em risco a vida e saúde das pessoas, sendo homens e mulheres, adultos e adolescentes, considerando que a escolha seja livre e informada 4 .

Entre os métodos que devem ser ofertados ao homem, mulher ou casal, está a vasectomia. A vasectomia consiste na esterilização ou contracepção masculina de caráter permanente. Depois da vasectomia, é necessária a realização do espermograma, exame que mostra que não existe espermatozoides no esperma ejaculado, logo, não será possível o homem engravidar a mulher ${ }^{5}$.

Dados do Sistema Único de Saúde (SUS) mostram o avanço da participação masculina no planejamento familiar. Em sete anos, a quantidade de vasectomias feitas pelo SUS cresceu 79\%. O número de cirurgias saltou de 19.103 , em 2003, para 34.144, em 2009. No Brasil, sua prevalência, apesar de ter aumentado nos últimos anos, ainda é baixa e pouco se sabe sobre como os homens que se submetem à cirurgia vivenciam a sua nova condição de esterilizados ${ }^{6-7}$.

Os serviços de saúde devem realizar ações educativas voltadas para o homem, para a orientação em contracepção e que discutam as relações de gênero, os mitos e os tabus envolvidos na vasectomia, no sentido de mostrar maiores esclarecimentos e permitir uma maior segurança na escolha do método ${ }^{8-9}$.

Diante dos indicadores mostrados, dos estereótipos que perpassam o procedimento da vasectomia, é necessário que se estimulem ações voltadas para o homem. Além de estimular a busca pela vasectomia como medida de contracepção, e distanciar a ideia de comprometimento sexual. Pode se afirmar que os estudos a respeito da temática são exíguos, uma vez que o homem é o protagonista do processo que envolve a realização da vasectomia, mesmo reconhecendo que tal decisão deve ser acertada e compartilhada pelo casal.

Mediante o exposto, identificou-se a seguinte questão de pesquisa: quais as percepções dos homens sobre o planejamento familiar e a vasectomia? O objetivo do estudo foi identificar e analisar as percepções de homens no grupo etário entre 25 e 59 anos sobre o planejamento familiar e a vasectomia, residentes na área de abrangência de uma Unidade de Saúde da Família do município de Vitória da Conquista-BA.

\section{MÉTODO}

Trata-se de um estudo de abordagem qualitativa, descritiva e exploratória. A pesquisa trabalha com o universo dos significados, dos motivos, das aspirações, das crenças, dos valores e das atitudes. Sendo esse conjunto de fatores entendido como parte da realidade social. Busca entender de forma aprofundada tudo que está relacionado ao homem, seja enquanto indivíduo, ou membro de um grupo ou sociedade ${ }^{10-11}$.

O cenário da pesquisa foi composto por uma Unidade de Saúde da Família (USF) do município de Vitória da Conquista. Para participar do estudo, os homens tinham que atender aos critérios de inclusão: ser residente da área de abrangência da unidade de saúde da família selecionada, ter idade entre 25 e 59 anos, concordar em participar da pesquisa e assinar o termo de compromisso livre e esclarecido (TCLE).

A amostra empregada para o desenvolvimento da pesquisa foi por saturação. A saturação é utilizada para estabelecer ou fechar o tamanho final de uma amostra em estudo, impossibilitando a entrada de novos componentes. A suspensão para a inclusão de novos participantes ocorre quando emerge, na avaliação do pesquisador, uma repetição de dados, não sendo necessária a continuidade da coleta de dados ${ }^{12}$.

Para a coleta de dados empregou-se a técnica de entrevista semiestruturada. Utilizou-se um roteiro previamente estabelecido, que por meio de uma conversa entre 0 pesquisador e 0 participante, dirigida pelo pesquisador, buscou responder aos objetivos propostos ${ }^{13}$. A realização da entrevista foi agendada previamente com os participantes da pesquisa, sendo o contato mediado pelos agentes comunitários de saúde, que levou o entrevistador ao encontro destes a partir de uma visita domiciliar. As entrevistas foram combinadas entre o participante $\mathrm{e}$ entrevistador, e aconteceram em locais, dias e horários mais apropriados para os participantes da pesquisa. 0 período da coleta de dados ocorreu entre junho e julho de 2016. 
A técnica utilizada para a análise dos dados foi a Análise de Conteúdo na modalidade Temática, que se desdobrou em três etapas.

A primeira, denominada de pré-análise, consistiu em um contato profundo e exaustivo com as transcrições por meio de repetidas leituras do material, no intuito de se garantir algumas normas de validade, sendo estas, exaustividade, representatividade, homogeneidade e pertinência.

Em um segundo momento, realizou-se a exploração do material, de modo a alcançar o núcleo de compreensão textual. Para isso, busca-se de acordo o conteúdo das falas a categorização onde se encontra categorias que consiste em um processo de redução do texto em palavras e expressões significativas.

E por fim, realizaram-se as interpretações qualitativas dos dados, articulando-as com o quadro teórico abordado inicialmente, bem como, a abertura para novas visões interpretativas ${ }^{14}$.

O projeto de pesquisa foi encaminhado ao Comitê de Ética em Pesquisa do Instituto Multidisciplinar em Saúde da Universidade Federal da Bahia (UFBA), sendo aprovado mediante o CAAE: 55213516.3.0000.5556.

Com o intuito de garantir a privacidade dos participantes da pesquisa, estes foram identificados pela letra $E$, seguida do número correspondente à ordem em que a entrevista aconteceu. Exemplo: E1 e E2.

\section{RESULTADOS}

A amostra consistiu de 13 homens com idade entre 25 a 59 anos, grupo etário determinado na PNAISH, houve predomínio da mesma faixa etária. Em relação ao estado civil dos participantes, seis possuíam uma união estável, cinco eram casados e dois solteiros, sendo que um dos solteiros já teve uma união estável anteriormente.

Quanto à escolaridade, sete apresentavam o ensino médio completo, três o ensino médio incompleto e três o ensino fundamental incompleto. No que se refere à profissão, observou-se que a maioria exercia a profissão de pedreiro.

A partir da análise dos dados, foram depreendidas duas categorias e quatro subcategorias por meio de recortes temáticos que se encontram apresentados no Quadro 1 e Quadro 2.

\section{DISCUSSÃO}

Para melhor compreensão da temática abordada foram depreendidas duas categorias: Olhares masculinos sobre o planejamento familiar, tendo como subcategoria: a importância do planejamento familiar sob a ótica masculina; fragilidade acerca do conhecimento/ participação masculina no planejamento familiar e 0 Antagonismo da vasectomia, tendo como subcategorias: benefícios da vasectomia; estereótipos/desconhecimento.

Quadro 1. Apresentação das categorias temáticas depreendidas. Vitória da Conquista, BA, Brasil, 2016.

\begin{tabular}{|c|c|c|}
\hline $\begin{array}{l}\text { Categorias } \\
\text { temáticas }\end{array}$ & Subcategorias & Recortes temáticos \\
\hline \multirow[t]{2}{*}{$\begin{array}{l}\text { Olhares } \\
\text { masculinos sobre } \\
\text { o planejamento } \\
\text { familiar }\end{array}$} & $\begin{array}{l}\text { A importância do } \\
\text { planejamento familiar sob a } \\
\text { ótica masculina }\end{array}$ & $\begin{array}{l}\text { Conheço o Billings, camisinha que é o que o pessoal mais usa, as pílulas } \\
\text { que eu acho, vou ser sincero para você, é um absurdo a mulher usar pílula, } \\
\text { por ser uma a dosagem muito alta de hormônios [...]. (E5) } \\
\text { [...]é mais para a mulher do que para o homem, a mulher operar mais } \\
\text { que para o homem, eu acho mais normal a mulher operar do que para o } \\
\text { homem [...]. (E11) } \\
\text { [...] Plano de família que eu faço para mim seria, casar, ter um a } \\
\text { estabilidade, emprego bom, montar uma casa e controlar a quantidade de } \\
\text { filhos que eu vou ter, para mim, planejamento familiar é isso. (E15) } \\
\text { [...] É muito importante ter esses métodos contraceptivos para evitar } \\
\text { gravidez indesejada, para evitar doença sexualmente transmissível, é } \\
\text { muito importante ter isso dentro da unidade de saúde. (E17) }\end{array}$ \\
\hline & $\begin{array}{l}\text { Fragilidade acerca do } \\
\text { conhecimento/participação } \\
\text { masculina no planejamento } \\
\text { familiar }\end{array}$ & $\begin{array}{l}\text { Nunca tive informação sobre isso, nunca procurei para saber não. Eu } \\
\text { trabalho muito, quase não tenho tempo para mexer assim nessas coisas. E } \\
\text { muitas vezes também, eu trabalho durante o dia e o posto não bate com } \\
\text { meu horário. (E4) } \\
\text { Eu não sei, eu só ouvi falar, mas eu não sei o que quer dizer com isso né? } \\
\text { Já vi a própria agente de saúde falando mas não prestei muita atenção } \\
\text { não. Mas deve ser construir uma família, ter um filho, um negócio já } \\
\text { planejado [...]. (E11) } \\
\text { Eu não tive interesse, no meu relacionamento ela que faz tudo. Pelo } \\
\text { menos um dos dois procura né? [...] (E12) } \\
\text { Já ouvi falar, mas eu vejo mais as mulheres falando, mãe, as meninas. } \\
\text { Eu não pergunto não, só vi o nome. Mas deve ser saber se a família, a } \\
\text { quantidade de pessoas que tem em casa, filhos, palestras [...]. (E14) } \\
\text { Eu acho que não, não sei nem o que é isso. O que é isso? Planejamento? } \\
\text { Familiar? (E16) }\end{array}$ \\
\hline
\end{tabular}

Fonte: dados da pesquisa. 
Quadro 2. Apresentação das categorias temáticas depreendidas. Vitória da Conquista, BA, Brasil, 2016.

\begin{tabular}{|c|c|c|}
\hline $\begin{array}{l}\text { Categorias } \\
\text { temáticas }\end{array}$ & Subcategorias & Recortes temáticos \\
\hline \multirow[t]{2}{*}{$\begin{array}{l}\text { O antagonismo da } \\
\text { vasectomia }\end{array}$} & Benefícios da vasectomia & $\begin{array}{l}{[\ldots] \text { Porque não é só a mulher que tem o dever de evitar, o homem também }} \\
\text { tem, ele tem que fazer a parte dele e ela fazer a parte dela [...] (E7). } \\
{[\ldots . .] \text { Tem mulheres que eu já vi falando que quando fazem essa cirurgia, elas }} \\
\text { perdem mais, elas se tornam mulheres frigidas, então são várias coisas [...] } \\
\text { Não agride o homem, como agride a mulher, então eu penso que é importante } \\
{[\ldots] \text { (E9). }} \\
{[\ldots] \text { E eu tenho dois colegas que já fez, não tem diferença neles não, só é bom }} \\
\text { que eles não engravidam as mulheres, eu vou pela cabeça deles (colegas). [...] } \\
\text { (E13) } \\
{[\ldots] \text { Já ouvi de um amigo que fez também, e ele não achou ruim não, pelo que }} \\
\text { eu vi, acho que a cirurgia é muito prática (E15). } \\
{[\ldots . .] \text { No meu caso mesmo, é porque a gente não tem filhos ainda, então não }} \\
\text { conseguiria fazer ainda essa cirurgia, mas eu pretendo fazer, até porque o } \\
\text { problema da minha esposa é irreversível [...] (E17). }\end{array}$ \\
\hline & $\begin{array}{l}\text { Estereótipos/ } \\
\text { desconhecimento }\end{array}$ & $\begin{array}{l}\text { [...] Os homens tem cisma em fazer a vasectomia, porque pensa que vai perder } \\
\text { a ereção ou até mesmo acontecer algum pequeno acidente lá [...] Eu acho que } \\
\text { eu não faria a vasectomia, porque existem outras formas (E5). } \\
{[\ldots . .] \text { Porque vai que lá no futuro se a gente não der certo com essa, vai que }} \\
\text { acontecesse de encontrar sim uma pessoa certa [...] E a pessoa queira ter um } \\
\text { filho e tal, e ai? [...] (E6). } \\
\text { Antes eu ficava meio assim, porque tinha pouca informação, cada um falava } \\
\text { uma coisa, que o homem ficava inválido, que causa isso, causa aquilo, eu } \\
\text { ficava com aquela coisa [...] (E8). }\end{array}$ \\
\hline
\end{tabular}

Fonte: dados da pesquisa.

\section{Categoria temática 1 - Olhares masculinos sobre o planejamento familiar}

$\mathrm{Na}$ presente categoria temática, foram identificados núcleos de sentido que convergiram para o olhar e conhecimento que os homens participantes do estudo tinham acerca do planejamento familiar.

Nesta vertente, o planejamento familiar é um evento que se orienta por ações preventivas e educativas e pela garantia de acesso de informações a todos, consiste na oferta de métodos e técnicas para a concepção e a anticoncepção, além da oferta de informações e acompanhamento, num contexto de escolha livre e informada4.

\subsection{A importância do planejamento familiar sob a ótica masculina}

A partir dos fragmentos das falas dos participantes, observaram-se elementos que evidenciaram a importância do planejamento familiar. No âmbito da saúde sexual e reprodutiva a PNAISH trouxe como proposta a possibilidade de implantar e maturar ações voltadas à saúde sexual e reprodutiva dos homens, destas incluemse a possibilidade de: ampliar e qualificar a atenção ao planejamento reprodutivo masculino; estimular a participação e a inclusão do homem nas ações de planejamento de sua vida sexual e reprodutiva, por meio de ações educativas; assegurar ao homem a oferta da contracepção cirúrgica voluntária masculina nos termos da legislação específica; promover a prevenção e o controle das doenças sexualmente transmissíveis e da infecção pelo Vírus da Imunodeficiência Humana (HIV)².
Quanto à importância do planejamento familiar sob a ótica masculina, a maioria dos homens participantes soube reconhecer os métodos contraceptivos dispensados pelo serviço de saúde, o que evidencia o conhecimento sobre modos de se fazer planejamento familiar. Notou-se que os homens que possuíam maior grau de instrução formal, consequentemente apresentaram um conhecimento mais acurado e facilidade em falar sobre o objeto de estudo. Aspecto semelhante pode ser identificado em outro estudo que aponta que a relação entre o conhecimento masculino acerca dos métodos contraceptivos pode estar relacionado com o elevado grau de escolaridade, o que contribui para uma maior adesão aos métodos contraceptivos ${ }^{15}$.

Um aspecto que contribui para a participação do homem na escolha do método contraceptivo está relacionado com o grau de instrução,entretanto, a compreensão masculina ainda é vista como superficial em relação aos métodos. A discreta apropriação, dos homens em relação aos métodos acaba sendo condicionada às informações acessadas por estes por meio de pessoas conhecidas e dos meios de comunicação ${ }^{16}$. Ademais, o conhecimento ganha substancialidade em relação aos métodos que suas parceiras mais utilizam ou dos métodos, os quais os homens também se envolvam, por exemplo: o preservativo, os anticoncepcionais orais, a laqueadura tubária e a vasectomia.

O conhecimento dos homens sobre os métodos contraceptivos se volta na grande maioria para o método utilizado pela companheira, uma vez que são elas que assumem com robustez a preocupação em se evitar a gravidez, aspecto este oriundo de uma construção sóciohistórica e que acaba por evidenciar a responsabilidade 
primeira da mulher ${ }^{16}$. Verificou-se na fala de alguns homens que ainda existe uma sobrecarga direcionada a mulher. Tal aspecto pode ser explicado, haja vista que a participação mais ativa da mulher em relação às ações de planejamento familiar possibilita uma aproximação maior com o conhecimento sobre os métodos contraceptivos e o fato de que a maioria dos métodos existentes é de uso feminino, contudo tal situação não exclui o homem de suas responsabilidades acerca da temática.

0 olhar fragilizado por parte de alguns participantes do estudo sobre o planejamento familiar traz consigo a atribuição à mulher como responsável pelo planejamento familiar do casal. Por outro lado, a PNAISH, em relação à saúde reprodutiva reforça a necessidade de participação do homem em tal processo, com vistas a romper com o imaginário e socialmente aceito de que tal atribuição seja direcionada apenas às mulheres, ao mesmo tempo em que estimula o acesso às informações e métodos contraceptivos ${ }^{2}$.

No serviço de atenção básica à saúde, o homem não é visto como segmento prioritário, além de utilizarem o serviço distintamente quando comparado à mulher. A maioria das mulheres participam ativamente das ações de prevenção de doenças e de promoção de saúde. Nesta perspectiva, entende-se que para uma maior adesão dos homens, as ações desenvolvidas pela atenção básica à saúde se reestruturem de modo a ofertar uma atenção ao público masculino que contemple, entre outros, a atenção acerca do planejamento familiar, elementos que se inserem nas ações dirigidas à saúde sexual e reprodutiva.

\subsection{Fragilidade acerca do conhecimento/participação masculina no planejamento familiar}

Na presente subcategoria, as falas apontam elementos que retratam a falta de interesse e/ou desconhecimento masculino sobre o planejamento familiar, sendo identificados os seguintes núcleos de sentido: a falta de tempo do homem relacionada ao trabalho e o planejamento familiar como responsabilidade da mulher.

Sob esse aspecto, nas falas de alguns entrevistados, eles referiram o tempo como um fator que dificultava a participação no planejamento familiar, uma vez que eles exerciam atividades laborais, observa-se, desta forma, a importância de ações voltadas ao público masculino, com horários flexíveis, informações e atividades direcionadas aos homens.

A percepção de que o homem é um ser invulnerável e viril, pode ser um dos fatores que afastam a busca pelo planejamento familiar, os mitos acerca da impotência sexual e o medo de adoecer também podem estar envolvidos nesse processo. Além disso, a indisponibilidade de serviços vinculados aos SUS, os serviços de atenção básica (adequação dos horários, longas filas e distância da residência e/ou trabalho) são barreiras que impedem os homens a buscarem pelo planejamento familiar ${ }^{3}$.

Constatou-se também que os homens não vivenciam o planejamento familiar da melhor forma, apontando como impedimento, a falta de tempo, uma vez que, por assumir atividades laborais extradomiciliares, os horários de disponibilidade muitas vezes são incompatíveis ao funcionamento dos serviços de saúde, ocasionando a responsabilidade de contracepção, principalmente, para a mulher ${ }^{17}$.

Outro aspecto que ganha destaque nas falas dos entrevistados, é a responsabilização da mulher em participar do planejamento familiar. Um estudo realizado com mulheres demonstra que a mulher assume o encargo da contracepção, pelo método ser de uso feminino e a participação do homem ocorre quando ela acredita ser necessária. A mulher é a responsável por ir até o serviço e por tomar todas as medidas para evitar a gravidez indesejada, mesmo que a decisão pela contracepção seja tomada pelo casal. Os homens consideravam-se satisfeitos com sua participação, pois a mulher não havia engravidado ainda, sendo irrelevante o fato do método ser agradável ou não para o casal, preocupando-se apenas com a limitação do número de filhos ${ }^{17}$.

Nessa vertente, nota-se a importância dos profissionais de saúde buscarem de forma ativa os homens, para que as responsabilidades sejam compartilhadas entre homens e mulheres.

\section{Categoria temática 2 - 0 antagonismo da vasectomia}

$\mathrm{Na}$ presente categoria temática, por meio dos fragmentos das falas dos homens, foram identificados núcleos do sentido que demonstram a compreensão dos homens quanto aos benefícios e os estereótipos ou desconhecimento relacionado à vasectomia.

Nesta perspectiva, o SUS, disponibiliza um leque de métodos contraceptivos, entre eles, os métodos de esterilização, que são: laqueadura tubária e vasectomia. A vasectomia é um método de esterilização cirúrgica, considerada segura e rápida. É a contracepção permanente realizada em homens. Para se submeter a tal procedimento o homem carece atender alguns pré-requisitos legais e a decisão deve ser do casal ${ }^{5}$.

Entre os pré-requisitos legais para se submeter à vasectomia, é necessário que o homem tenha idade superior a vinte e cinco anos de idade ou, pelo menos, tenha dois filhos vivos. 0 prazo mínimo requerido é de sessenta dias entre a manifestação da vontade em realizar o procedimento até o ato cirúrgico, período este, necessário para que o homem interessado tenha acesso ao serviço de regulação da fecundidade, incluindo aconselhamento por equipe multidisciplinar, visando desencorajar a esterilização precoce. Na vigência da sociedade conjugal, é necessário o consentimento expresso de ambos os cônjuges ${ }^{18}$.

\subsection{Benefícios da vasectomia}

A partir das frações das falas dos entrevistados, notam-se elementos que demonstram os benefícios da 
vasectomia, sendo identificados os seguintes núcleos do sentido: a saúde da companheira atrelado à escolha pela vasectomia, o número de filho e as facilidades para realizar a vasectomia.

Conforme o relato dos homens entrevistados, entre os determinantes que consideram a vasectomia como método de escolha foi citado à preocupação com a saúde da companheira, tendo em vista que a laqueadura tubária é uma cirurgia mais invasiva quando comparada a vasectomia e pode tornar a mulher frígida ${ }^{19}$.

Em uma pesquisa realizada com 202 homens demonstra que a opção pela vasectomia surgiu da sensibilização pela utilização dos métodos contraceptivos que faziam mal à saúde e eram utilizados por suas companheiras, percebeuse que os homens não demonstraram arrependimento pela escolha do método ${ }^{7}$.

Outros aspectos relevantes que emergiram das falas dos participantes referem-se ao número de filhos e a opinião de pessoas próximas confiáveis, que já realizaram o procedimento, observou-se como fatores consideráveis para optar pela vasectomia. 0 homem busca a vasectomia para demarcar a quantidade de filhos.

Em uma pesquisa realizada com 20 casais, evidenciouse que a ideia de fazer a vasectomia partiu do homem que considerou a quantidade de filhos que já possuíam e a impossibilidade de criar mais filhos. A ideia de fazer a vasectomia amadureceu mediante as conversas com pessoas confiáveis que já tinham realizado o procedimento ${ }^{19}$.

Sob tal aspecto, os fragmentos das falas dos homens que ganham destaque, são as facilidades encontradas no procedimento da vasectomia, sendo uma cirurgia menor e com recuperação rápida. Em uma pesquisa, 46,8\% dos homens consideraram a vasectomia mais prática e segura quando comparada à laqueadura tubária. $\mathrm{O}$ que corrobora com um estudo em que casais, preferiam a vasectomia por ser uma cirurgia de pequeno porte e possuir menores riscos e incômodos para os homens ${ }^{8-19}$.

Destarte, as falas dos homens demonstraram a preocupação com as condições de saúde da sua família e o controle de filhos o que proporciona a divisão da responsabilidade com a mulher.

\subsection{Vasectomia: estereótipos/ desconhecimentos}

Por meio dos trechos das falas dos entrevistados, observaram-se elementos que corroboram com os estereótipos ou desconhecimento dos homens no que tange a vasectomia. A vasectomia encontra-se permeada por mitos e fragilidades no acesso à orientação, o que pode reproduzir no homem o sentimento do medo.

Sob tal aspecto, do grupo de homens entrevistados observou-se a ambivalência em relação à vasectomia, foram identificados elementos que apontam para a vasectomia como um método contraceptivo eficaz, porém outros entrevistados já a percebem de forma distinta, com receio e medo.

Nesta vertente, um estudo quantitativo realizado na cidade de Recife, com homens no pré-operatório de vasectomia demonstrou que os três maiores medos apresentados pelos entrevistados foram: o medo da dor na administração da anestesia, da impotência após o procedimento e da dor após o término do efeito da anestesia ${ }^{8}$.

Portanto, os relatos dos entrevistados, salientam que o medo está interligado a fragilidade no acesso à orientação. Existem alguns tabus percebidos nas falas dos homens que corroboram com uma pesquisa, que traz como principais medos, a diminuição da ejaculação, a impotência sexual, alteração no desejo sexual e por temerem um inchaço nos testículos. Os dados demonstram as limitações dos homens acerca do conhecimento sobre o procedimento da vasectomia e consequentemente da participação do homem no planejamento familiar'

No Brasil, atualmente, existe uma lacuna no conhecimento referente ao método contraceptivo de esterilização cirúrgica masculina, no que se refere às possíveis consequências da opção pela vasectomia na vida dos homens que se submeteram ao método contraceptivo. Provavelmente, tal explicação pode estar associada à baixa popularidade e prevalência da vasectomia em nosso país ${ }^{7}$.

Nas falas dos entrevistados, observou-se a necessidade de um processo educativo mais abrangente, relacionado ao planejamento familiar, com abordagem da contracepção de maneira ampla, o que pode proporcionar o término dos estigmas e tabus envolvendo a vasectomia.

\section{CONCLUSÃO}

Os resultados encontrados permitiram perceber as percepções dos homens sobre o planejamento familiar e a vasectomia. Identificou-se que, em geral, os homens conhecem os métodos contraceptivos de forma limitada e têm uma participação mínima no planejamento. Desta forma a mulher é reconhecida como única responsável pelo planejamento familiar que deve ser vivenciado pelo casal.

Ademais, os homens participantes do estudo apontaram como fator de impedimento para a participação no planejamento familiar à falta de tempo, os horários de disponibilidade incompatíveis ao funcionamento dos serviços de saúde. Os homens reconheceram os benefícios da vasectomia e associaram a promoção de melhoria da saúde da companheira e não ter filhos, entretanto, percebem-se as limitações de conhecimento do homem quanto à vasectomia, pois tal método ainda está cercado por mitos e fragilidades.

Diante dos resultados, para uma maior adesão do homem a ação do planejamento familiar faz-se necessária incluir os homens nas orientações sobre saúde sexual, reprodutiva, contracepção e vasectomia. Para que isso aconteça, a inclusão 
deve começar no acolhimento na unidade, com treinamento da equipe e adoção de medidas que permitam que o homem sinta-se valorizado como usuário. Ações inovadoras podem ser adotadas como ampliação de horários de atendimento, atividades assistenciais da USF no local de trabalho dos homens, residências, campos de futebol e outros locais onde haja maior concentração da população masculina. Entre ações prioritárias podem ser realizadas atividades educativas, com elaboração e distribuição de materiais voltados para a população masculina, buscando adequação da linguagem e desmistificar os mitos e fragilidades associados à vasectomia.

A pesquisa apresenta limitações de um estudo qualitativo, inseridos no local e tempo onde foi desenvolvida. Desta forma, não se deve generalizar os resultados, mas aprofundar as percepções dos homens sobre o planejamento familiar/vasectomia. Recomendamse estudos sobre o tema, abrangendo outras regiões do Brasil e que esses novos estudos possibilitem dar voz aos homens e mulheres, a fim de visualizar a maneira como se compreendem no contexto do planejamento familiar. Espera-se, que este estudo possa contribuir para o aperfeiçoamento do cuidado e acolhimento por meio dos trabalhadores de saúde para proporcionar uma assistência de qualidade, respeitando as singularidade de mulheres e homens e suas escolhas sexuais e reprodutivas.

\section{REFERÊNCIAS}

1. Julião GG, Weigelt LD. Atenção à Saúde do Homem em Unidades de Estratégia de Saúde da Família. R. Enfermagem UFSM. 2011 mai/ago; 1(2): 144-152.

2. Brasil. Ministério da Saúde. Secretaria de Atenção à Saúde. Departamento de Ações Programáticas Estratégicas. Política Nacional de Atenção Integral à Saúde do Homem. Brasília, 2009a.

3. Casarin ST, Siqueira HCH. Planejamento familiar e a saúde do homem na visão das enfermeiras. Esc. Anna Nery Esc. Enferm. 2014; 18(4): 662-8.

4. Brasil. Ministério da Saúde. Cadernos de atenção básica. Secretaria de Atenção à Saúde, Departamento de Atenção Básica. Saúde sexual e saúde reprodutiva.1. ed., 1. reimpr. Ministério da Saúde, Brasília, p.302. 2013.

5. Brasil. Ministério da Saúde. Secretaria de Atenção à Saúde. Departamento de Ações Programáticas Estratégicas. Direitos sexuais, direitos reprodutivos e métodos anticoncepcionais. Brasília, 2009b.

6. Brasil. Ministério da Saúde. Publicação da Assessoria de Comunicação Social do Ministério da Saúde. A saúde pública no Brasil: Saúde, um bem coletivo [Internet]. 2010. [acesso 25 set 2016]; Disponível em: http://observasaude.fundap. sp.gov.br/BibliotecaPortal/Acervo/Sa\%C3\%BAde/Saude\%20 Publica\%20no\%20Brasil.pdf.

7. Marchi NM,Alvarenga AT, Osis MJD, Godoy HMA, Guimarães MCB, Bahamondes L. Consequências da vasectomia: experiências de homens que se submeteram à cirurgia em Campinas (São Paulo), Brasil. Saúde Soc. 2011 Jul/Set; 20(3): 568-578.
8. Costa JA, Souza MAO, Ximenes VL, Adreto L. Vasectomia: perfil dos candidatos à cirurgia em um Hospital Escola do Recife-PE. Rev. Interdisc. 2013; 6(2): 38-47.

9. Silva AN, Murai HC. Vasectomia no contexto do planejamento familiar. Rev. Enferm UNISA. 2010; 11(2): 90-93.

10. Minayo MC. de S, (org.). $O$ desafio da pesquisa social. In: Pesquisa Social. Teoria, método e criatividade. Petrópolis: Vozes, 2013. p.9-29.

11. Canzonieri AM. Etapas da escolha da pesquisa. In: Metodologia da pesquisa qualitativa em saúde, Petrópolis: Vozes, 2010a. p.37-71.

12. Fontanella BJB, Turato ER. Barreiras na relação clínico-paciente em dependentes de substâncias psicoativas procurando tratamento. Rev. Saúde Pública. 2002; 36(4): 439-447.

13. Canzonieri AM. Etapas de desenvolvimento da pesquisa. In: Metodologia da pesquisa qualitativa em saúde, Petrópolis: Vozes, 2010b. p.73-97.

14. Minayo MCS. Técnicas de Análise de Material Qualitativo. In:__ O desafio do conhecimento: pesquisa qualitativa em saúde. São Paulo: Hucitec, 2007. Cap. 11, p.303-360.

15. Espírito SDC, Tavares NJ. A visão masculina sobre métodos contraceptivos em uma comunidade rural da Bahia, Brasil. Cad Saude Publica. 2004; 20(2) :562-569.

16. Brito RS, Santos DLA. Contextualizando o homem no planejamento familiar: um estudo bibliográfico. Rev Pesqui Cuid Fundam. 2011; 3(1): 1720-1728.

17. Morais ACB, Ferreira AG, Almeida KL, Quirino GS. Participação masculina no planejamento familiar e seus fatores intervenientes. Revista de Enferm UFSM. 2014, Jul/Set; 4(3): 498-508.

18. Brasil. Lei $n^{\circ} 9.263$, de 12 de janeiro de 1996. Regula o $\S 7^{\circ}$ do artigo 226 da Constituição Federal, que trata do planejamento familiar, estabelece penalidades e dá outras providências. Diário Oficial da República Federativa do Brasil, DF,[Internet] 1996. [acesso 30 set 2016]; Disponível em: http://www. planalto.gov.br/ccivil_03/LEIS/L9263.htm

19. Marchi NM, Alvarenga, AT, Osis MJD, Bahamondes L. Opção pela vasectomia e relações de gênero. Cad. Saúde Pública, 2003 Agosto; 19(4): 1017-1027. 